\title{
Impact of Drought Index Detection Thresholds - the Case of Babna District, Bangladesh
}

\author{
Md. Mostafizur Rahman ${ }^{1}$, M. Sayedur Rahman ${ }^{2}$ \\ ${ }^{1}$ Associate Professor, Data Mining Research Group, Department of Statistics, University of Rajshahi, Bangladesh \\ mostafiz_bd21@yahoo.com \\ ${ }^{2}$ Professor, Environmental Research Group, Department of Statistics, University of Rajshahi, Bangladesh \\ rmsayedur@gmail.com
}

\begin{abstract}
The climate plays important role in the agriculture production in any country. Rainfall is one of the most important factors which affect non-irrigated crop. Water deficits and excess water are the greatest constraints for rain fed rice yields. Agricultural drought is mainly inadequacy of rainfall. In this study an attempt has been made to apply Markov Chain model techniques for drought index detection with different threshold value and find out the most drought prone decade of Pabna district by Markov Chain model. The daily rainfall data set for 55 years during the period 1961-2015 is considered in this study. The daily rainfall data were reducing 5 , 7 and 10 days and considered threshold value $2.5 \mathrm{~mm}, 5.0 \mathrm{~mm}$ and $7.5 \mathrm{~mm}$. We calculate the Drought Index from the first transition probability matrix and then estimate with higher transition probability matrix. When the higher transition probability matrix became stable, then we estimate the DI. The empirical study showed that the decade 1961-1969, 1970-1979, 1980-1989 was more drought prone than the decade 1990-1999, 2000-2009 and 2010-2015. Among these decades, the decade 1961-1969 was maximum drought prone of all of these three threshold value for 5 days, 7 days and 10 days data in case of Pabna district. This study also showed that the following district is affected by chronic drought proneness in the 1st TPM for threshold value $2.5 \mathrm{~mm}$ but at higher TPM both stations are affected different drought proneness some are severe, some are moderate, some are mild some are occasional. It indicates that if we calculate the drought index decade wise both stations are affected by chronic drought proneness at the 1st TPM but due to climate change at higher TPM the drought proneness are not chronic at all. For any data point if we consider different threshold value for identifying drought index then we may conclude that if we increase the threshold value than it decrease the DI value. This study will contribute to policy formulation and strategic planning in the areas such as, agricultural practices and crop diversification, investments in irrigation development works and allocation of water to different uses.
\end{abstract}

Keywords: Drought Index, Different time period, Threshold Value, Markov Chain Model and Pabna

\section{Introduction}

Bangladesh is one of the most vulnerable countries to climate change because of its disadvantageous geographic location; flat and low-lying topography; dense population; high level of poverty; reliance of many livelihoods on climate sensitive sectors, particularly crop agriculture and fisheries; and inefficient institutional and poor infrastructure. Large parts of the country are flooded each year and on the other hand drought has adversely affecting rice production and therefore food supply. In Bangladesh, dry season continued for seven months (November-May) and it this time rainfall is normally low. But drought mostly appears in premonsoon (March-May) and postmonsoon (OctoberNovember) seasons ([20], [8]).

After the devastating effect in USA in 1987-1988, in Somalia in 1991-93, and similar effect in Ethiopia few years ago and in the shale region of Africa in the late 1980's the word Drought received attention in the recent years ([1]). Rain water is one of the most important factors of agriculture planning. Rainfall varies from year to year and place to place, sometimes leading to the occurrence of drought. During the climate season if drought occurs, it effects both crop season, increasing the food shortage and miser of the people. When varies combinations of agriculture planning of the physical factors of the environment produce in internal water stress in the crop plants sufficient to reduce their productivity in case of drought time ([3]-[6]).

Earlier studies from different parts of the world indicate that global warming has distorted the precipitation patterns which causes the occurring of frequent extreme weather events, such as floods, droughts, and rainstorms ([42], [38], [43], [44]), [10]). Although there are number of studies have been carried out on rainfall patterns ([13], [21], [2], [40], [41], [14]) but only few works have been found on rainfall trends and extremes in case of Bangladesh. Rahman [34] used a stochastic simulated Markov Chain Model for daily rainfall data in case of agricultural production in Bangladesh. Karmakar and Khatun [18] re-investigated a similar study on rainfall extremes during the southwest monsoon season. Mckee et al. [24] used Standardized Precipitation Index (SPI) to identify the wet and dry months from rainfall time series. Mann-Kendall trend analysis ([23], [19]) and the Sen's slope ([39]) method are used to detect the presence of significant change and the magnitude of change respectively, Byun and Wilhite [11] developed the EDI which specifically designed to calculate daily drought severity. Recurring drought is prevalent in the northwest region compared to other parts of the country because of its high temperature and low rainfall characteristics (Shahid and Behrawan, [41]). Pabna is one of the districts of these regions which produce sufficient amount of food grain. Paul 
[26] argued that this area is relatively dry, receiving much lower rainfall compared to the rest of country ([28] -[33]).

So, the aim of this study is to investigate the impact of threshold value to detect Drought Index using Markov Chain model at different time scales for Pabna district Bangladesh. The rest of the paper is organized as follows: Section 2 presents the characteristics of study area, Section 3 present Methodology, Section 4 present the Result and Discussion and finally Conclusion is provided in Section 5.

\section{Study Area}

Pabna District is situated in north-western part Bangladesh. It is one of the southernmost district of Rajshahi Division.
It's area are $2371.50 \mathrm{sq} \mathrm{km}$, located in between $23^{\circ} 48^{\prime}$ and $24^{\circ} 21^{\prime}$ north latitudes and in between $89^{\circ} 00^{\prime}$ and $89^{\circ} 44^{\prime}$ east longitudes. It is bounded by Natore and Sirajganj districts on the north, Padma river, Rajbari and Kushtia districts on the south, Manikganj and Sirajganj districts and Jamuna river on the east, Padma River, Natore and Kushtia districts on the west. The average high temperature is $37.8{ }^{\circ} \mathrm{C}$ and the average low is $9.2{ }^{\circ} \mathrm{C}$. Annual rainfall averages 1,467 millimetres. Characteristically the soil of the district is divided into four, viz flood plains of the Ganges, Karatoya, Jamuna and Barind Tract. Main rivers are Padma, Baral, Jamuna, Ichamati, Hurasagar. The map of Pabna district is given in Figure 1.

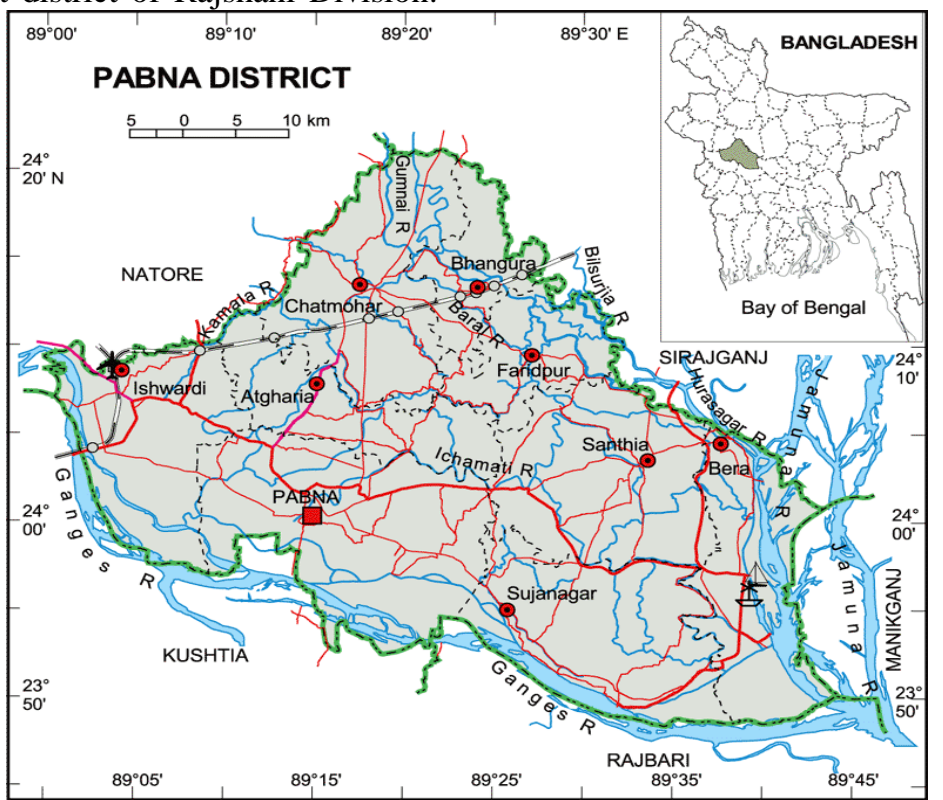

Figure 1: Map of Pabna district (Source: https://zesun35geo.webs.com/map.htm)

\subsection{Data Source \& Smoothing}

The daily rainfall data of 55 years from 1961 to 2015 of Ishurdi station (Pabna district) is collected from Bangladesh meteorological department. There were some missing data over that range. Collecting the data from Rajshahi Station, there were two missing year $(1969,1970)$ and about almost three missing months (March, April and May in 1971) which were not recorded. The missing value were random, however continuous missing data for one month to several months also evident in some stations. By using Microsoft Excel data, we have separated this time interval in 5, 7 and 10 days series format then we estimate missing value by using SPSS, then it was finally ready to apply our methodology. After that we use R program to analyze under Markov chain model for threshold value $2.5 \mathrm{~mm}, 5.0 \mathrm{~mm}$ and $7.5 \mathrm{~mm}$ of rainfall.

\section{Methodology}

Different indexes have been used to detect the drought. Plamer ([27]) proposed Plamer Drought Severity Index (PSDI) to detect the drought in USA. Later some modification was done by Heddinghaus and Sabol in1991 ([12]). McKeeet et. al. [24] measured meteorological flood and drought by using only precipitation with Standardized
Precipitation Index (SPI). Here in this paper we use Markov Chain model to detect drought.

\subsection{Markov Chain Model}

Markov chain probability model is based on the assumption that the state of any day depends only on the state of the previous day. A two state Markov chain model involves the calculations of two conditional probabilities (1) $\alpha$, the probability of a wet week following dry week and (2) $\beta$, the probability of a dry week. The conditional probabilities for two state Markov chain model is given below:

\begin{tabular}{|c|c|c|c|}
\hline \multirow{3}{*}{ Present state } & & Dry & Wet \\
\cline { 2 - 4 } & Dry & $1-\alpha$ & $\alpha$ \\
\cline { 2 - 4 } & Wet & $\beta$ & $1-\beta$ \\
\hline
\end{tabular}

Let us consider the conditional probabilities which are denoted by $P_{0}=\operatorname{Pr}\{(W / D\}$ and $P_{1}=\operatorname{Pr}\{W / W\}$.

This sequence is irreducible Markov chain with two argotic states. Its stationary probability distribution has a probability of success $P=p_{01} /\left(1-\left(p_{11}-p_{01}\right)\right)$. 


\subsection{Markov Chain Model of Order M}

In a Markov process the state and parameter spaces are considered to be discrete and the dependency of the state is called Markovian dependence ([22]). A Markov chain model of order $\mathrm{m}$ is a sequence of trails of the outcomes $\mathrm{m}$. According to the sequence of random variables $\left\{X_{n}\right\}$ forms a Markov chain of order $\mathrm{m}$, if given a fixed $\mathrm{m}$, for all possible values of the variables $X_{n}(n=0,1,2, \ldots)$ it is true that

$$
\begin{aligned}
& \operatorname{Pr}\left[X_{n}=j \mid X_{0}=i_{0}, X_{1}=i_{1}, \ldots, X_{n-m}\right] \\
& \operatorname{Pr}\left[X_{n}=j \mid X_{n-m}=i_{n-m}\right]
\end{aligned}
$$

\subsection{Method of Markov Chain Model}

Anderson and Goodman (1957) described the sequences in daily rainfall occurrences by a simple Markov chain model. Rahman ([36], [37]), Meghla and Rahman [25], Kamruzzaman et al., ([15], [16]) and Banik et.al. [9] also used Markov chain model for identify drought index ([28], [29]). The theory of Markov chain is given below:

Let $X_{0}, X_{1}, X_{2}, \ldots, X_{n}$ be random variables which is identically distributed and taking only two values, 0 and 1 , with probability one, i.e.

$$
X n=\left\{\begin{array}{l}
0 \text { if the } n \text {-th week is dry } \\
1 \text { if the } n \text {-th week is wet }
\end{array}\right.
$$

Firstly, it may be assume that,

$\mathrm{P}\left(\mathrm{X}_{\mathrm{n}}+1=\mathrm{X}_{\mathrm{n}}+1, \mathrm{X}_{\mathrm{n}}=\mathrm{X}_{\mathrm{n}}, \mathrm{X}_{\mathrm{n}}-1=\mathrm{X}_{\mathrm{n}}-1, \ldots, \mathrm{X}_{0}=\mathrm{x}_{0}\right)=\mathrm{P}\left(\mathrm{X}_{\mathrm{n}}+1\right.$

$\left.=\mathrm{X}_{\mathrm{n}}+1, \mathrm{X}_{\mathrm{n}}=\mathrm{X}_{\mathrm{n}}\right)$

where $X_{0}, X_{1}, \ldots, X_{n}+1 €\{0,1\}$.

In other words, it is assumed that probability of wetness of any week depends only on whether the previous week was wet or dry. Given the event on previous week, the probability of wetness is assumed independent of further preceding weeks. So, the stochastic process $\left\{X_{n}, n=\right.$ $0,1,2 \ldots \ldots\}$ is a Markov chain.

Considering the transition matrix as;

$\mathrm{P}_{\mathrm{ij}}=\left[\begin{array}{ll}P_{00} & P_{01} \\ P_{10} & P_{11}\end{array}\right]$

Where, $P_{i j}=P\left(X_{1}=j \mid X_{0}=i\right) i, j=0,1$. Note $P_{00}+P_{01}=1$ and $\mathrm{P}_{10}+\mathrm{P}_{11}=1$

The higher order Transition Probability Matrix (TPM) is given below:

$$
P_{i j}^{(m+1)}=\sum_{r} p_{i r} p_{r j}^{(m)}
$$

Therefore, we get the stable point at $T^{i} \cong T^{i+1}$, where, $\mathrm{i}=1$, $2,3,4, \ldots, \mathrm{n}$

\subsection{Index of Drought Proneness}

The probability of a week to be wet given that previous week was also wet is given by $P_{11}$. When $P_{11}$ is large, the chance of wet weeks is also large. But only a small value of $P_{11}$ may not indicate high drought proneness. In this case, large value of $P_{01}$ implies a large number of short wet spells which can prevent occurrence of drought. Hence, an index of drought proneness may be defined as $D I=P_{11} * P_{01}$
The index of drought proneness is bounded by zero and one. Higher the value of $D I$, lower will be the degree of drought proneness. The extent of drought proneness is given in Table 1.

Table 1: The index of drought proneness

\begin{tabular}{|c|c|}
\hline Criteria & Degree of drought proneness \\
\hline $0.000 \leq \mathrm{DI} \leq 0.125$ & Chronic \\
\hline $0.125 \leq \mathrm{DI} \leq 0.180$ & Severe \\
\hline $0.180 \leq \mathrm{DI} \leq 0.235$ & Moderate \\
\hline $0.235 \leq \mathrm{DI} \leq 0.310$ & Mild \\
\hline $0.310 \leq \mathrm{DI} \leq 1.000$ & Occasional \\
\hline
\end{tabular}

Source: Banik, et al. [9]

\section{Result and Discussion}

Markov Chain Model had been used to evaluate Drought Index using Higher Transition Probability Matrix. An index based on the parameters of this model has been suggested for agriculture drought measurement in Pabna district. For investigating the impact of threshold value we consider threshold value $2.5 \mathrm{~mm}, 5.0 \mathrm{~mm}$ and $7.5 \mathrm{~mm}$ for calculating the drought index.

\subsection{Drought Index at different decade from 1961 to 2015 for Pabna}

The drought index based on $\mathrm{r}$ a infall for the decade from 1961-1969 at 5 days, 7 days and 10 days with three threshold value $2.5 \mathrm{~mm}, 5.0 \mathrm{~mm}$ and $7.5 \mathrm{~mm}$ are reported in

\begin{tabular}{|c|c|c|c|c|c|c|c|}
\hline \multirow{2}{*}{ Year } & \multirow{2}{*}{$\begin{array}{c}\text { Threshold } \\
\text { value }\end{array}$} & \multirow{2}{*}{$P_{01}$} & \multirow[b]{2}{*}{$P_{11}$} & \multicolumn{2}{|c|}{ 1st TPM } & \multicolumn{2}{|c|}{ Higher TPM } \\
\hline & & & & DI & Comment & DI & Comment \\
\hline \multirow{3}{*}{5 days } & $2.5 \mathrm{~mm}$ & 0.043 & 0.950 & .0408 & Chronic & 0.212 & Moderate \\
\hline & $5.0 \mathrm{~mm}$ & 0.040 & 0.945 & .0378 & Chronic & 0.175 & Severe \\
\hline & $7.5 \mathrm{~mm}$ & 0.041 & 937 & .0384 & Chronic & 0.153 & Severe \\
\hline \multirow{3}{*}{7 days } & $2.5 \mathrm{~mm}$ & 0.03 & 0.968 & .0309 & Chronic & 0.249 & Mild \\
\hline & $5.0 \mathrm{~mm}$ & 0.027 & 0.967 & .0261 & Chronic & 0.212 & Moderate \\
\hline & $7.5 \mathrm{~mm}$ & 0.026 & 0.964 & .0269 & Chronic & 0.190 & Moderate \\
\hline \multirow{3}{*}{10 days } & $2.5 \mathrm{~mm}$ & 0.023 & 0.980 & .0225 & Chronic & 0.291 & Mild \\
\hline & $5.0 \mathrm{~mm}$ & 0.024 & .976 & 0.0234 & Chronic & 0.249 & Mild \\
\hline & $7.5 \mathrm{~mm}$ & 0.024 & 973 & .0233 & Chronic & 0.230 & Iodera \\
\hline
\end{tabular}
Table 2 and Figure 2.

Table 2: Drought index with different threshold value for the decade (1961-1969)

From the above Table 2 we observed that, for 5 days data for the decade 1961-1969 the three threshold values showed chronic drought prone at their first Transition Probability Matrix (TPM) and at the higher TPM the drought converted into moderate, severe and severe respectively for the threshold vale $2.5 \mathrm{~mm}, 5.0 \mathrm{~mm}$ and $7.5 \mathrm{~mm}$. For 7 days data with $2.5 \mathrm{~mm}, 5.0 \mathrm{~mm}$ and $7.5 \mathrm{~mm}$ threshold value present the chronic drought prone at $1^{\text {st }}$ Transition Probability Matrix (TPM) and at higher TPM the drought index turned into mild, moderate and moderate respectively. The threshold value $2.5 \mathrm{~mm}, 5.0 \mathrm{~mm}$ and $7.5 \mathrm{~mm}$ showed the chronic drought at the first TPM and this index converted into mild, mild and moderate respectively for 10 days data for the decade 1961 to 1969 . From figure 2 we found that the different 5 days, 7 days and 10 days data with $2.5 \mathrm{~mm}$, $5.0 \mathrm{~mm}$ and $7.5 \mathrm{~mm}$ threshold value starting from chronic drought prone at its first TMP but due to climate change it 
produced different drought prone at higher TMP and it being stable at different stages. From this figure it is clear that 5 days data is more drought prone than 7 days and 10 days data. This figure also indicated that the 5 days data the three threshold value $2.5 \mathrm{~mm}, 5.0 \mathrm{~mm}$ and $7.5 \mathrm{~mm}$ take 48th, 47th and 44th steps respectively to become stable, for 7 days data these three threshold value takes 63 th, 67 th and 65 th steps and for 10 days data it takes 87 th, 78th and 73 th steps respectively.

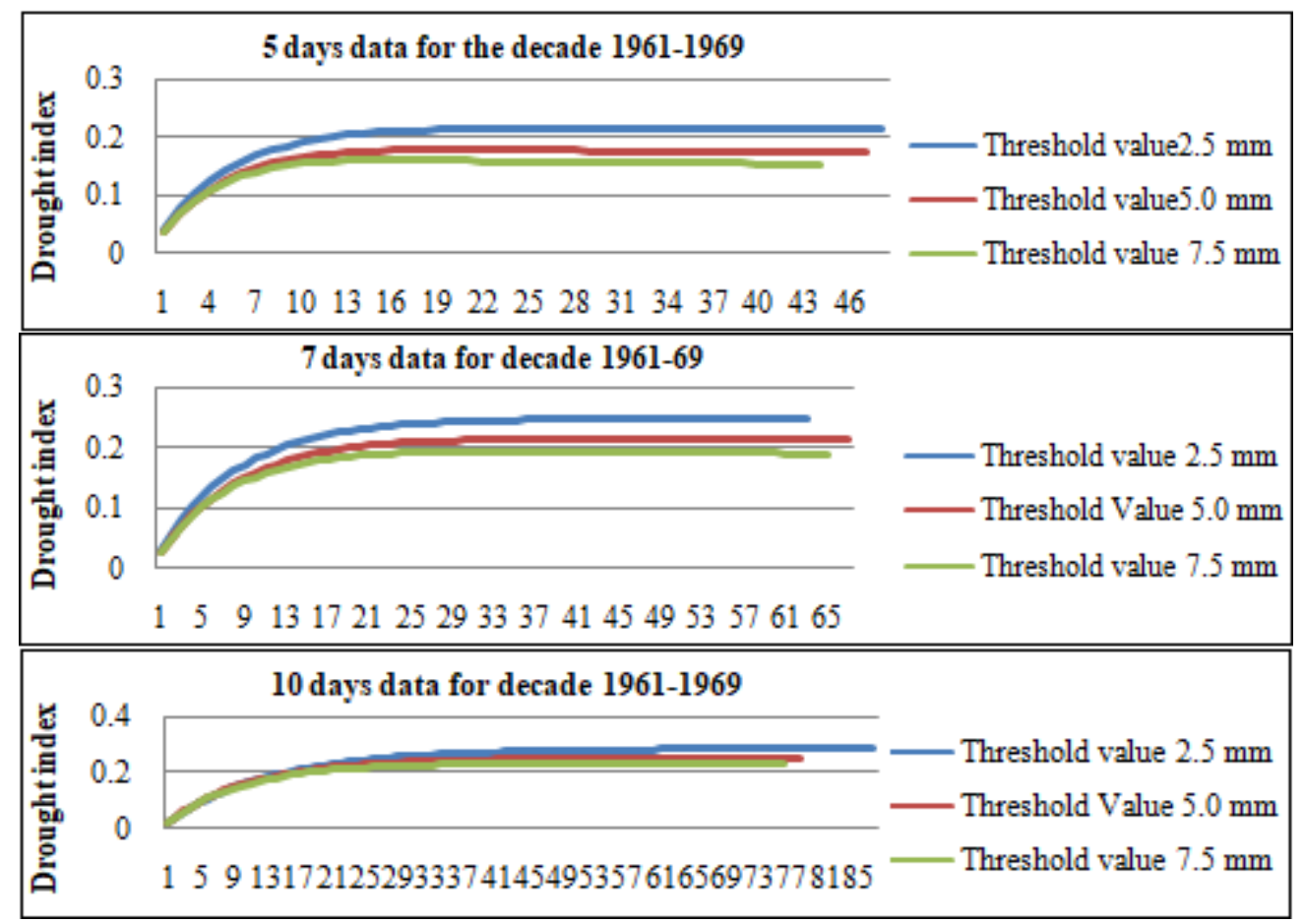

Figure 2: Drought index scenario for with different threshold value for the decade 1961-1969

The drought index based on rainfall for the decade from 1970-1979 at 5 days, 7 days and 10 days with three threshold value $2.5 \mathrm{~mm}, 5.0 \mathrm{~mm}$ and $7.5 \mathrm{~mm}$ are reported in Table 3 and Figure 3.
Table 3: Drought index with different threshold value for the decade (1970-1979)

\begin{tabular}{|c|c|c|c|c|c|c|c|}
\hline \multirow{2}{*}{ Year } & $\begin{array}{c}\text { Threshold } \\
\text { value }\end{array}$ & $P_{01}$ & $P_{11}$ & \multicolumn{2}{|c|}{ 1st TPM } & \multicolumn{2}{c|}{ Higher TPM } \\
\cline { 3 - 8 } & & & DI & Comment & DI & Comment \\
\hline \multirow{2}{*}{$\begin{array}{c}5 \\
\text { days }\end{array}$} & $2.5 \mathrm{~mm}$ & 0.066 & 0.945 & 0.0623 & Chronic & 0.298 & Mild \\
\cline { 2 - 8 } & $5.0 \mathrm{~mm}$ & 0.066 & 0.936 & 0.0617 & Chronic & 0.257 & Mild \\
\cline { 2 - 8 } & $7.5 \mathrm{~mm}$ & 0.062 & 0.931 & 0.0577 & Chronic & 0.222 & Moderate \\
\hline \multirow{2}{*}{$\begin{array}{c}7 \\
\text { days }\end{array}$} & $2.5 \mathrm{~mm}$ & 0.054 & 0.964 & 0.0520 & Chronic & 0.361 & Occasional \\
\cline { 2 - 8 } & $5.0 \mathrm{~mm}$ & 0.052 & 0.960 & 0.0499 & Chronic & 0.319 & Occasional \\
\cline { 2 - 8 } & $7.5 \mathrm{~mm}$ & 0.049 & 0.958 & 0.0469 & Chronic & 0.287 & Mild \\
\hline \multirow{2}{*}{$\begin{array}{c}10 \\
\text { days }\end{array}$} & $2.5 \mathrm{~mm}$ & 0.041 & 0.979 & 0.0401 & Chronic & 0.433 & Occasional \\
\cline { 2 - 8 } & $5.0 \mathrm{~mm}$ & 0.037 & 0.903 & 0.0361 & Chronic & 0.390 & Occasional \\
\cline { 2 - 8 } & $7.5 \mathrm{~mm}$ & 0.036 & 0.976 & 0.0351 & Chronic & 0.357 & Occasional \\
\hline
\end{tabular}

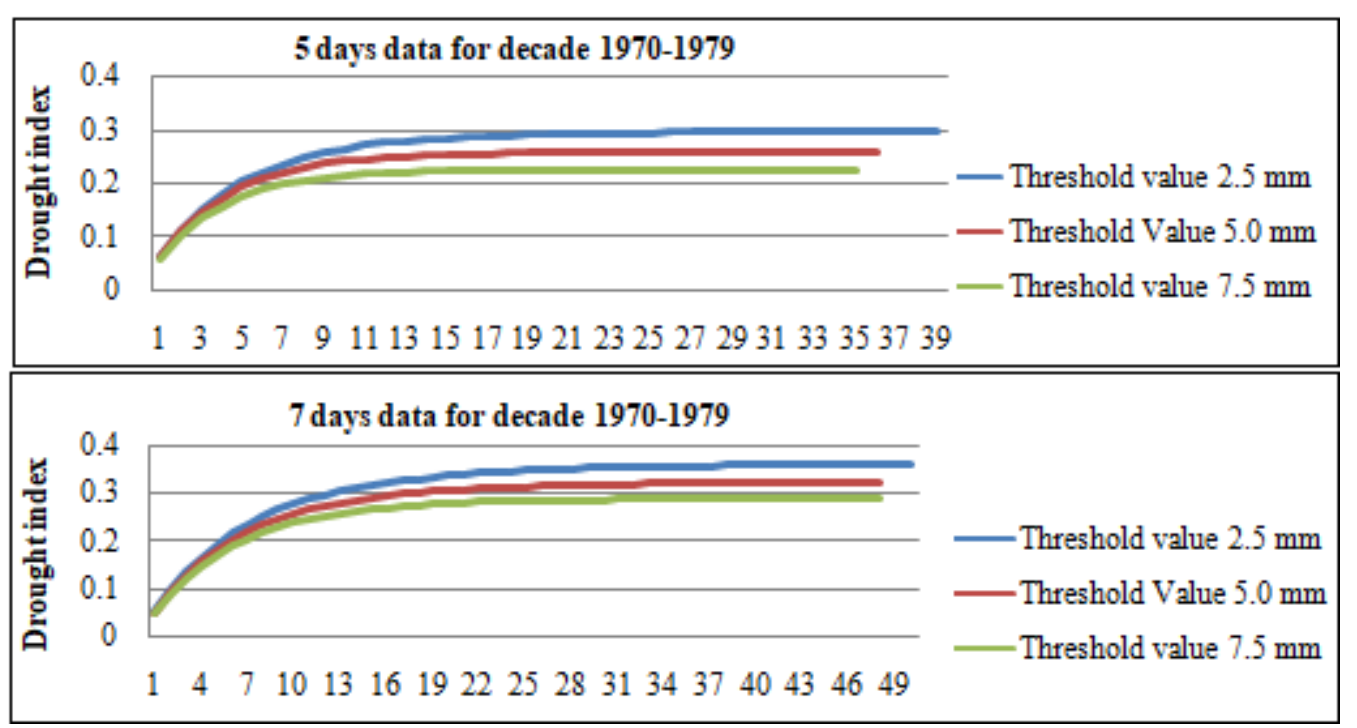

Volume 8 Issue 11, 2021 


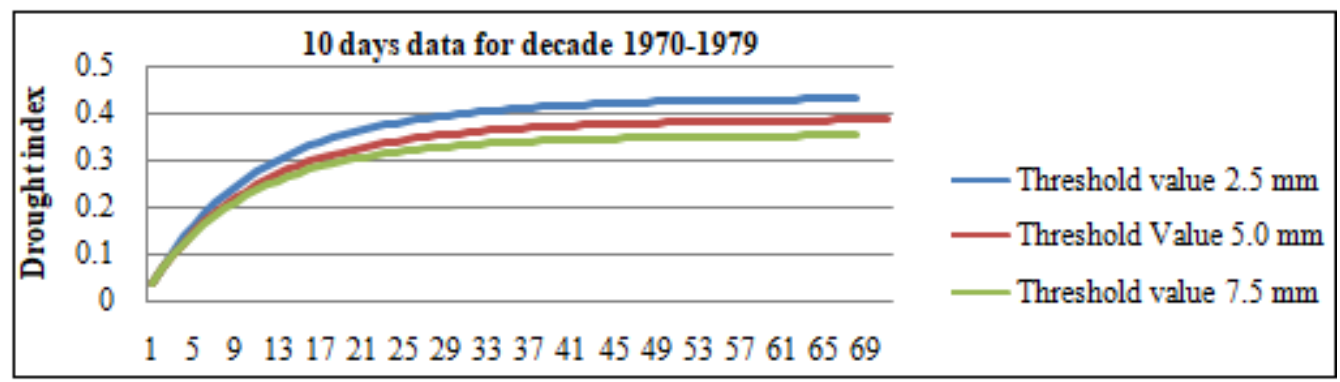

Figure 3: Drought index scenario for with different threshold value for the decade 1970-1979

From the above Table 3 we observed that, for 5 days data for the decade 1970-1979 the three threshold values showed chronic drought prone at their first Transition Probability Matrix (TPM) and at the higher TPM the drought converted into mild, mild and moderate respectively for the threshold vale $2.5 \mathrm{~mm}, 5.0 \mathrm{~mm}$ and $7.5 \mathrm{~mm}$. For 7 days data with 2.5 $\mathrm{mm}, 5.0 \mathrm{~mm}$ and $7.5 \mathrm{~mm}$ threshold value present the chronic drought prone at $1^{\text {st }}$ Transition Probability Matrix (TPM) and at higher TPM the drought index turned into occasional, occasional and mild respectively. The threshold value $2.5 \mathrm{~mm}, 5.0 \mathrm{~mm}$ and $7.5 \mathrm{~mm}$ showed the chronic drought at the first TPM and all of these indices converted into occasional drought prone for 10 days data for the decade 1970 to 1979 . From figure 3 we found that the different 5 days data the three threshold value $2.5 \mathrm{~mm}, 5.0$ $\mathrm{mm}$ and $7.5 \mathrm{~mm}$ take 39th, 36th and 35th steps respectively to become stable, for 7 days data these three threshold value takes 50th, 48th and 48th steps and for 10 days data it takes 68th, 71th and 71th steps respectively to become stable.

The drought index based on $\mathrm{r}$ a infall for the decade from 1980-1989 at 5 days, 7 days and 10 days with three threshold value $2.5 \mathrm{~mm}, 5.0 \mathrm{~mm}$ and $7.5 \mathrm{~mm}$ are reported in Table 4 and Figure 4.
Table 4: Drought index with different threshold value for the decade (1980-1989)

\begin{tabular}{|c|c|c|c|c|c|c|c|}
\hline \multirow{2}{*}{ Year } & $\begin{array}{c}\text { Threshold } \\
\text { value }\end{array}$ & \multirow{2}{*}{$P_{01}$} & $P_{11}$ & \multicolumn{2}{|c|}{ 1st TPM } & \multicolumn{2}{c|}{ Higher TPM } \\
\cline { 3 - 8 } & & & DI & Comment & DI & Comment \\
\hline \multirow{2}{*}{$\begin{array}{c}5 \\
\text { days }\end{array}$} & $2.5 \mathrm{~mm}$ & 0.070 & 0.935 & 0.0654 & Chronic & 0.268 & Mild \\
\cline { 2 - 8 } & $5.0 \mathrm{~mm}$ & 0.066 & 0.929 & 0.0613 & Chronic & 0.232 & Moderate \\
\cline { 2 - 8 } & $7.5 \mathrm{~mm}$ & 0068 & 0.914 & 0.0621 & Chronic & 0.192 & Moderate \\
\hline \multirow{2}{*}{$\begin{array}{c}7 \\
\text { days }\end{array}$} & $2.5 \mathrm{~mm}$ & 0.058 & 0.959 & 0.0556 & Chronic & 0.340 & Occasional \\
\cline { 2 - 8 } & $5.0 \mathrm{~mm}$ & 0.054 & 0.955 & 0.0515 & Chronic & 0.296 & Mild \\
\cline { 2 - 8 } & $7.5 \mathrm{~mm}$ & 0.053 & 0.948 & 0.0502 & Chronic & 0.258 & Mild \\
\hline \multirow{2}{*}{$\begin{array}{c}10 \\
\text { days }\end{array}$} & $2.5 \mathrm{~mm}$ & 0.042 & 0.977 & 0.0410 & Chronic & 0.414 & Occasional \\
\cline { 2 - 8 } & $5.0 \mathrm{~mm}$ & 0.038 & 0.976 & 0.0370 & Chronic & 0.370 & Occasional \\
\cline { 2 - 7 } & $7.5 \mathrm{~mm}$ & 0.038 & 0.971 & 0.0369 & Chronic & 0.327 & Occasional \\
\hline
\end{tabular}

From the above Table 4 we observed that, for 5 days data for the decade 1980-1989 the three threshold values showed chronic drought prone at their first Transition Probability Matrix (TPM) and at the higher TPM the drought converted into mild, moderate and moderate respectively for the threshold vale $2.5 \mathrm{~mm}, 5.0 \mathrm{~mm}$ and $7.5 \mathrm{~mm}$. For 7 days data with $2.5 \mathrm{~mm}, 5.0 \mathrm{~mm}$ and $7.5 \mathrm{~mm}$ threshold value present the chronic drought prone at $1^{\text {st }}$ Transition Probability Matrix (TPM) and at higher TPM the drought index turned into occasional, mild and mild respectively. The threshold value $2.5 \mathrm{~mm}, 5.0 \mathrm{~mm}$ and $7.5 \mathrm{~mm}$ showed the chronic drought at the first TPM and all of these indices converted into occasional drought prone for 10 days data for the decade 1980 to 1989 . From figure 4 we found that the different 5 days data the three threshold value $2.5 \mathrm{~mm}, 5.0$ $\mathrm{mm}$ and $7.5 \mathrm{~mm}$ take $35 \mathrm{th}, 34 \mathrm{th}$ and 31 th steps respectively to become stable, for 7 days data these three threshold value takes 46th, 46th and 42th steps and for 10 days data it takes 66th, 67 th and 63th steps respectively to become stable.

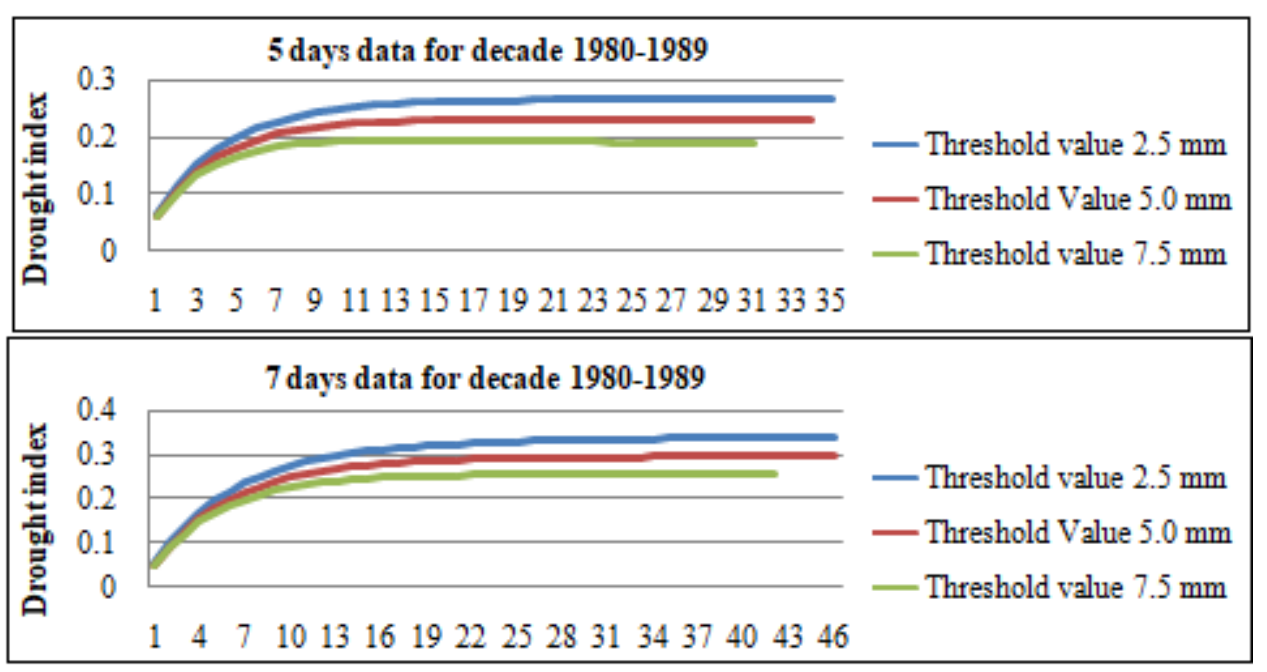




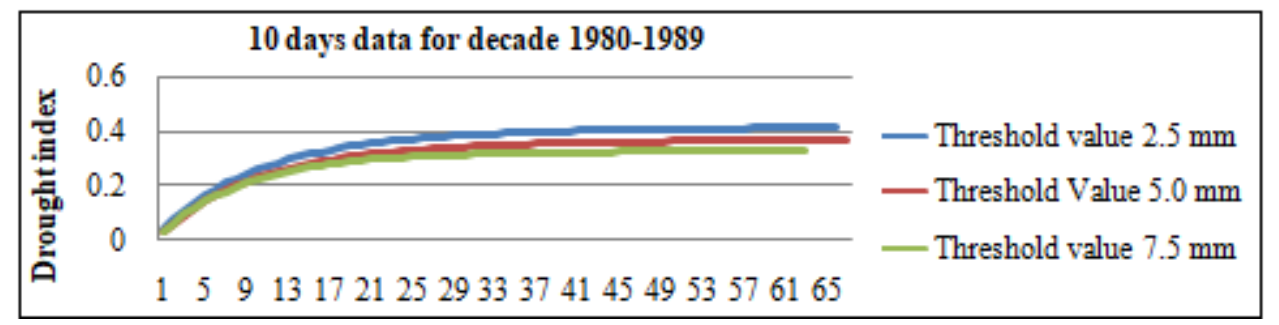

Figure 4: Drought index scenario for with different threshold value for the decade 1980-1989

The drought index based on $\mathrm{r}$ a infall for the decade from 1990-1999 at 5 days, 7 days and 10 days with three threshold value $2.5 \mathrm{~mm}, 5.0 \mathrm{~mm}$ and $7.5 \mathrm{~mm}$ are reported in Table 5 and Figure 5.

Table 5: Drought index with different threshold value for the decade (1990-1999)

\begin{tabular}{|c|c|c|c|c|c|c|c|}
\hline \multirow{2}{*}{ Year } & $\begin{array}{c}\text { Threshold } \\
\text { value }\end{array}$ & \multirow{2}{*}{$P_{01}$} & \multirow{2}{*}{$P_{11}$} & \multicolumn{2}{|c|}{ 1st TPM } & \multicolumn{2}{c|}{ Higher TPM } \\
\cline { 3 - 7 } & & DI & Comment & DI & Comment \\
\hline \multirow{2}{*}{$\begin{array}{c}5 \\
\text { days }\end{array}$} & $2.5 \mathrm{~mm}$ & 0.075 & 0.934 & 0.0700 & Chronic & 0.280 & Mild \\
\cline { 2 - 7 } & $5.0 \mathrm{~mm}$ & 0.072 & 0.928 & 0.0668 & Chronic & 0.248 & Mild \\
\cline { 2 - 7 } & $7.5 \mathrm{~mm}$ & 0.075 & 0.912 & 0.0684 & Chronic & 0.218 & Moderate \\
\hline \multirow{2}{*}{$\begin{array}{c}7 \\
\text { days }\end{array}$} & $2.5 \mathrm{~mm}$ & 0.060 & 0.959 & 0.057 & Chronic & 0.354 & Occasional \\
\cline { 2 - 7 } & $5.0 \mathrm{~mm}$ & 0.054 & 0.958 & 0.051 & Chronic & 0.317 & Occasional \\
\cline { 2 - 7 } & $7.5 \mathrm{~mm}$ & 0.055 & 0.952 & 0.052 & Chronic & 0.285 & Mild \\
\hline \multirow{2}{*}{$\begin{array}{c}10 \\
\text { days }\end{array}$} & $2.5 \mathrm{~mm}$ & 0.050 & 0.974 & 0.048 & Chronic & 0.436 & Occasional \\
\cline { 2 - 7 } & $5.0 \mathrm{~mm}$ & 0.043 & 0.975 & 0.041 & Chronic & 0.391 & Occasional \\
\cline { 2 - 7 } & $7.5 \mathrm{~mm}$ & 0.040 & 0.973 & 0.038 & Chronic & 0.358 & Occasional \\
\hline
\end{tabular}

chronic drought prone at their first Transition Probability Matrix (TPM) and at the higher TPM the drought converted into mild, mild and moderate respectively for the threshold vale $2.5 \mathrm{~mm}, 5.0 \mathrm{~mm}$ and $7.5 \mathrm{~mm}$. For 7 days data with 2.5 $\mathrm{mm}, 5.0 \mathrm{~mm}$ and $7.5 \mathrm{~mm}$ threshold value present the chronic drought prone at $1^{\text {st }}$ Transition Probability Matrix (TPM) and at higher TPM the drought index turned into occasional, occasional and mild respectively. The threshold value $2.5 \mathrm{~mm}, 5.0 \mathrm{~mm}$ and $7.5 \mathrm{~mm}$ showed the chronic drought at the first TPM and all of these indices converted into occasional drought prone for 10 days data for the decade 1990 to 1999 . From figure 5 we found that the different 5 days data the three threshold value $2.5 \mathrm{~mm}, 5.0$ $\mathrm{mm}$ and $7.5 \mathrm{~mm}$ take $33 \mathrm{th}, 33 \mathrm{th}$ and 31 th steps respectively to become stable, for 7 days data these three threshold value takes 45th, 46th and 44th steps and for 10 days data it takes 59th, 63th and 64th steps respectively to become stable.

From the above Table 5 we observed that, for 5 days data for the decade 1990-1999 the three threshold values showed

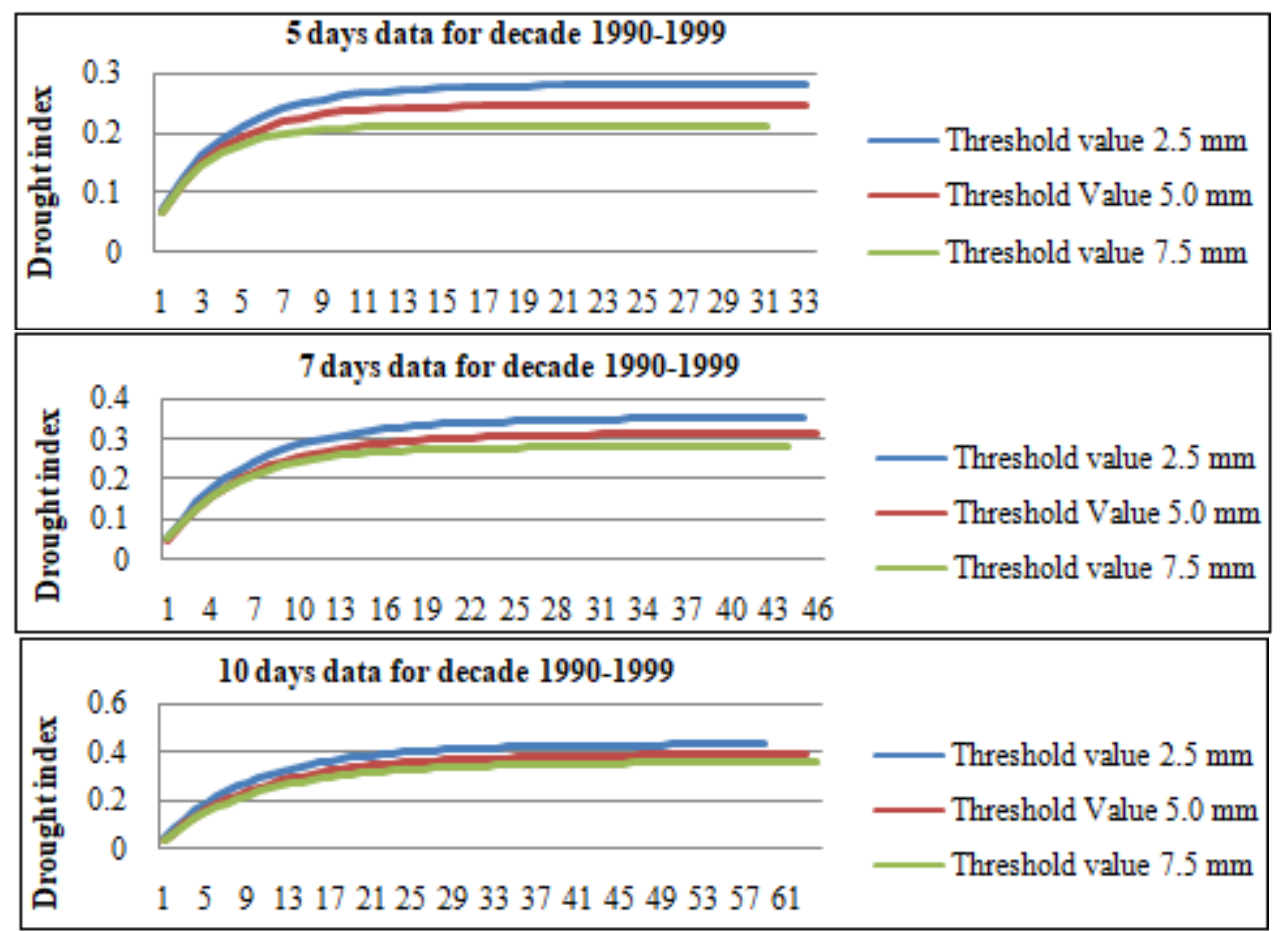

Figure 5: Drought index scenario for with different threshold value for the decade 1990-1999

The drought index based on $\mathrm{r}$ a infall for the decade from 2000-2009 at 5 days, 7 days and 10 days with three threshold value $2.5 \mathrm{~mm}, 5.0 \mathrm{~mm}$ and $7.5 \mathrm{~mm}$ are reported in Table 6 and Figure 6. 
Table 6: Drought index with different threshold value for the decade (2000-2009)

\begin{tabular}{|c|c|c|c|c|c|c|c|}
\hline \multirow{2}{*}{ Year } & $\begin{array}{c}\text { Threshold } \\
\text { value }\end{array}$ & \multirow{2}{*}{$P_{01}$} & $P_{11}$ & \multicolumn{2}{|c|}{ 1st TPM } & \multicolumn{2}{c|}{ Higher TPM } \\
\cline { 5 - 8 } & $2.5 \mathrm{~mm}$ & 0.073 & 0.927 & 0.067 & Chronic & 0.251 & Mild \\
\hline \multirow{3}{*}{5 days } & $5.0 \mathrm{~mm}$ & 0.072 & 0.918 & 0.066 & Chronic & 0.218 & Moderate \\
\cline { 2 - 8 } & $7.5 \mathrm{~mm}$ & 0.069 & 0.907 & 0.062 & Chronic & 0.182 & Moderate \\
\hline \multirow{3}{*}{7 days } & $2.5 \mathrm{~mm}$ & 0.058 & 0.956 & 0.055 & Chronic & 0.320 & Occasional \\
\cline { 2 - 8 } & $5.0 \mathrm{~mm}$ & 0.058 & 0.950 & 0.055 & Chronic & 0.288 & Mild \\
\cline { 2 - 8 } & $7.5 \mathrm{~mm}$ & 0.056 & 0.944 & 0.052 & Chronic & 0.251 & Mild \\
\hline \multirow{3}{*}{10 days } & $2.5 \mathrm{~mm}$ & 0.039 & 0.977 & 0.038 & Chronic & 0.396 & Occasional \\
\cline { 2 - 8 } & $5.0 \mathrm{~mm}$ & 0.033 & 0.978 & 0.032 & Chronic & 0.365 & Occasional \\
\cline { 2 - 8 } & $7.5 \mathrm{~mm}$ & 0.038 & 0.972 & 0.036 & Chronic & 0.332 & Occasional \\
\hline
\end{tabular}
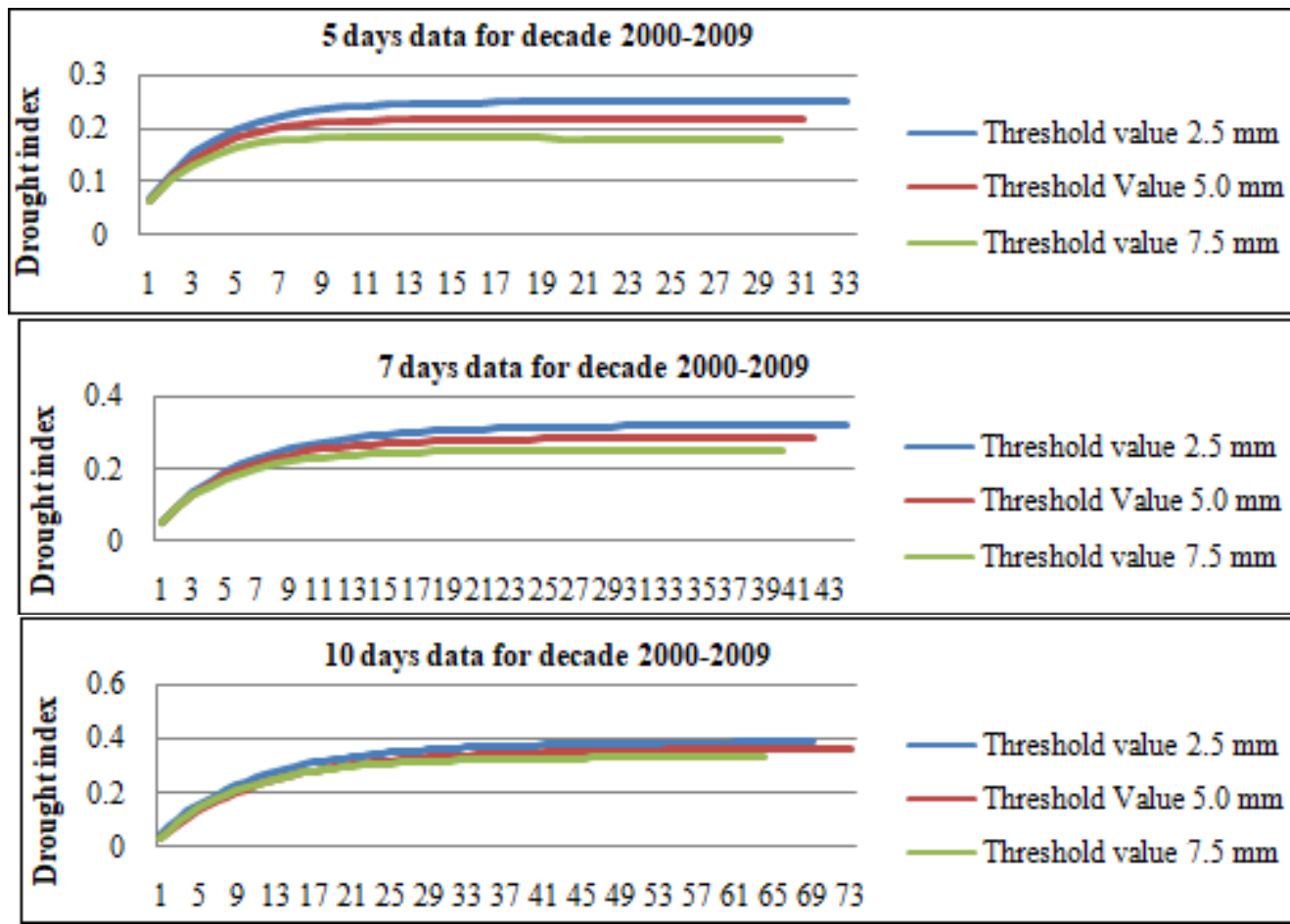

Figure6: Drought index scenario for with different threshold value for the decade 2000-2009

From the above Table 6 we observed that, for 5 days data for the decade 2000-2009 the three threshold values showed chronic drought prone at their first Transition Probability Matrix (TPM) and at the higher TPM the drought converted into mild, moderate and moderate respectively for the threshold vale $2.5 \mathrm{~mm}, 5.0 \mathrm{~mm}$ and $7.5 \mathrm{~mm}$. For 7 days data with $2.5 \mathrm{~mm}, 5.0 \mathrm{~mm}$ and $7.5 \mathrm{~mm}$ threshold value present the chronic drought prone at $1^{\text {st }}$ Transition Probability Matrix (TPM) and at higher TPM the drought index turned into occasional, mild and mild respectively. The threshold value $2.5 \mathrm{~mm}, 5.0 \mathrm{~mm}$ and $7.5 \mathrm{~mm}$ showed the chronic drought at the first TPM and all of these indices converted into occasional drought prone for 10 days data for the decade 2000 to 2009 . From figure 5 we found that the different 5 days data the three threshold value $2.5 \mathrm{~mm}, 5.0$ $\mathrm{mm}$ and $7.5 \mathrm{~mm}$ take 33th, 31th and 30th steps respectively to become stable, for 7 days data these three threshold value takes 44th, 42th and 40th steps and for 10 days data it takes 69th, 73th and 64th steps respectively to become stable. The drought index based on $\mathrm{r}$ a infall for the decade from 2010-2015 at 5 days, 7 days and 10 days with three threshold value $2.5 \mathrm{~mm}, 5.0 \mathrm{~mm}$ and $7.5 \mathrm{~mm}$ are reported in Table 7 and Figure 7.

Table 7: Drought index with different threshold value for the decade (2010-2015)

\begin{tabular}{|c|c|c|c|c|c|c|c|}
\hline \multirow{2}{*}{ Year } & Threshold & \multirow{2}{*}{$\mathrm{P}_{01}$} & \multirow{2}{*}{$\mathrm{P}_{11}$} & \multicolumn{2}{|c|}{ 1st TPM } & \multicolumn{2}{c|}{ Higher TPM } \\
\cline { 5 - 8 } & value & & DI & Comment & DI & Comment \\
\hline \multirow{3}{*}{5 days } & $2.5 \mathrm{~mm}$ & 0.068 & 0.920 & 0.0625 & Chronic & 0.213 & Moderate \\
\cline { 2 - 8 } & $5.0 \mathrm{~mm}$ & 0.064 & 0.916 & 0.0586 & Chronic & 0.187 & Moderate \\
\cline { 2 - 8 } & $7.5 \mathrm{~mm}$ & 0.067 & 0.893 & 0.0598 & Chronic & 0.149 & Severe \\
\hline \multirow{3}{*}{7 days } & $2.5 \mathrm{~mm}$ & 0.057 & 0.950 & 0.0541 & Chronic & 0.284 & Mild \\
\cline { 2 - 8 } & $5.0 \mathrm{~mm}$ & 0.051 & 0.950 & 0.0484 & Chronic & 0.251 & Mild \\
\cline { 2 - 8 } & $7.5 \mathrm{~mm}$ & 0.058 & 0.934 & 0.0541 & Chronic & 0.219 & Moderate \\
\hline \multirow{3}{*}{10 days } & $2.5 \mathrm{~mm}$ & 0.037 & 0.976 & 0.036 & Chronic & 0365 & Occasional \\
\cline { 2 - 8 } & $5.0 \mathrm{~mm}$ & 0.036 & 0.973 & 0.0350 & Chronic & 0.326 & Occasional \\
\cline { 2 - 8 } & $7.5 \mathrm{~mm}$ & 0.040 & 0.968 & 0.0387 & Chronic & 0.319 & Occasional \\
\hline
\end{tabular}


From the above Table 7 we observed that, for 5 days data for the decade 2010-2015 the three threshold values showed chronic drought prone at their first Transition Probability Matrix (TPM) and at the higher TPM the drought converted into moderate, moderate and mild respectively for the threshold vale $2.5 \mathrm{~mm}, 5.0 \mathrm{~mm}$ and $7.5 \mathrm{~mm}$. For 7 days data with $2.5 \mathrm{~mm}, 5.0 \mathrm{~mm}$ and $7.5 \mathrm{~mm}$ threshold value present the chronic drought prone at $1^{\text {st }}$ Transition Probability Matrix (TPM) and at higher TPM the drought index turned into mild, mild and moderate respectively. The threshold value $2.5 \mathrm{~mm}, 5.0 \mathrm{~mm}$ and $7.5 \mathrm{~mm}$ showed the chronic drought at the first TPM and all of these indices converted into occasional drought prone for 10 days data for the decade 2010 to 2015 .

From the Table 2, Table 3, Table 4, Table 5, Table 6 and Table 7 we found that for 5 days data the Drought Index
(DI) is higher in case of threshold value $2.5 \mathrm{~mm}$ both in first TPM and higher TPM and it was decreasing for threshold value $5.0 \mathrm{~mm}$ as well as $7.5 \mathrm{~mm}$. In case of 7 days data the drought index was higher in case of $2.5 \mathrm{~mm}$ and it decreases in case of $5.0 \mathrm{~mm}$ and $7.5 \mathrm{~mm}$. The other two 7 days and 10 days data also presented the similar result i.e. if we increase the threshold value than it decrease the DI value.

From figure 7 we found that the different 5 days data the three threshold value $2.5 \mathrm{~mm}, 5.0 \mathrm{~mm}$ and $7.5 \mathrm{~mm}$ take 33 th, 33th and 29th steps respectively to become stable, for 7 days data these three threshold value takes 42th, 44th and 38th steps and for 10 days data it takes 68th, 66th and 59th steps respectively to become stable.

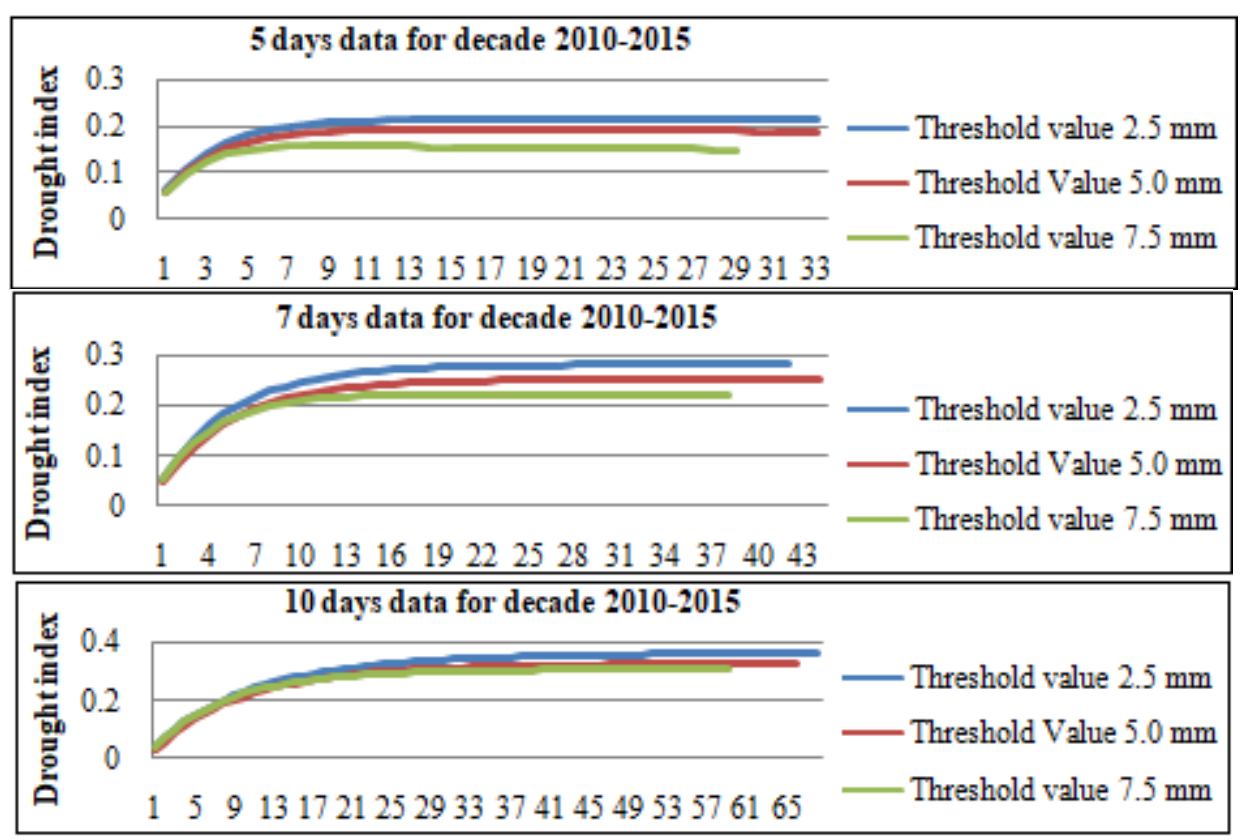

Figure 7: Drought index scenario for with different threshold value for the decade 2010-2015

\subsection{Overall Drought Index for whole period from 1961 to 2015 for Pabna}

The drought index based on $\mathrm{r}$ a infall for the decade from $1961-2015$ at 5 days, 7 days and 10 days with three threshold value $2.5 \mathrm{~mm}, 5.0 \mathrm{~mm}$ and $7.5 \mathrm{~mm}$ are reported in Table 8 and Figure 8.

Table 8: Overall Drought index with different threshold value for the period (1961-2015)

\begin{tabular}{|c|c|c|c|c|c|c|c|}
\hline \multirow{2}{*}{ Year } & $\begin{array}{c}\text { Threshold } \\
\text { value }\end{array}$ & \multirow{2}{*}{$P_{01}$} & $P_{11}$ & \multicolumn{2}{c|}{ 1st TPM } & \multicolumn{2}{c|}{ Higher TPM } \\
\cline { 3 - 8 } & & DI & Comment & DI & Comment \\
\hline \multirow{2}{*}{$\begin{array}{c}5 \\
\text { days }\end{array}$} & $2.5 \mathrm{~mm}$ & 0.066 & 0.936 & 0.0610 & Chronic & 0.257 & Mild \\
\cline { 2 - 8 } & $5.0 \mathrm{~mm}$ & 0.063 & 0.929 & 0.0585 & Chronic & 0.222 & Moderate \\
\cline { 2 - 8 } & $7.5 \mathrm{~mm}$ & 0.063 & 0.917 & 0.0577 & Chronic & 0.188 & Moderate \\
\hline \multirow{2}{*}{$\begin{array}{c}7 \\
\text { days }\end{array}$} & $2.5 \mathrm{~mm}$ & 0.053 & 0.960 & 0.0508 & Chronic & 0.320 & Occasional \\
\cline { 2 - 8 } & $5.0 \mathrm{~mm}$ & 0.049 & 0.957 & 0.0468 & Chronic & 0.284 & Mild \\
\cline { 2 - 8 } & $7.5 \mathrm{~mm}$ & 0.049 & 0.951 & 0.0465 & Chronic & 0.251 & Mild \\
\hline \multirow{2}{*}{$\begin{array}{c}10 \\
\text { days }\end{array}$} & $2.5 \mathrm{~mm}$ & 0.038 & 0.977 & 0.0371 & Chronic & 0.309 & Occasional \\
\cline { 2 - 8 } & $5.0 \mathrm{~mm}$ & 0.035 & 0.976 & 0.0341 & Chronic & 0.350 & Occasional \\
\cline { 2 - 7 } & $7.5 \mathrm{~mm}$ & 0.035 & 0.973 & 0.0340 & Chronic & 0.320 & Occasional \\
\hline
\end{tabular}

From the above Table we observed that, for 5 days data for entire time period 1961-2015 the three threshold values showed chronic drought prone at their first Transition Probability Matrix (TPM) and at the higher TPM the drought converted into mild, moderate and moderate respectively for the threshold vale $2.5 \mathrm{~mm}, 5.0 \mathrm{~mm}$ and 7.5 $\mathrm{mm}$. For 7 days data with $2.5 \mathrm{~mm}, 5.0 \mathrm{~mm}$ and $7.5 \mathrm{~mm}$ threshold value present the chronic drought prone at $1^{\text {st }}$ Transition Probability Matrix (TPM) and at higher TPM the drought index turned into occasionally, mild and mild respectively. The threshold value $2.5 \mathrm{~mm}, 5.0 \mathrm{~mm}$ and 7.5 $\mathrm{mm}$ showed the chronic drought at the first TPM and all of these indices converted into occasional for 10 days data for whole time period 1961-2015. From figure 5 we found that the different 5 days data the three threshold value $2.5 \mathrm{~mm}$, $5.0 \mathrm{~mm}$ and $7.5 \mathrm{~mm}$ take 36th, 35th and 32th steps respectively to become stable, for 7 days data these three threshold value takes 48th, 48th and 45th steps and for 10 days data it takes 68th, 70th and 66th steps respectively to become stable. This Table also showed that for 5 days data the Drought Index (DI) is higher in case of threshold value $2.5 \mathrm{~mm}$ both in first TPM and higher TPM and it was 
decreasing for threshold value $5.0 \mathrm{~mm}$ as well as $7.5 \mathrm{~mm}$. In case of 7 days data the drought index was higher in case of $2.5 \mathrm{~mm}$ and it decreases in case of threshold value $5.0 \mathrm{~mm}$ and $7.5 \mathrm{~mm}$. The other two 7 days and 10 days data also presented the similar result i.e. if we increase the threshold value than it decrease the DI value.
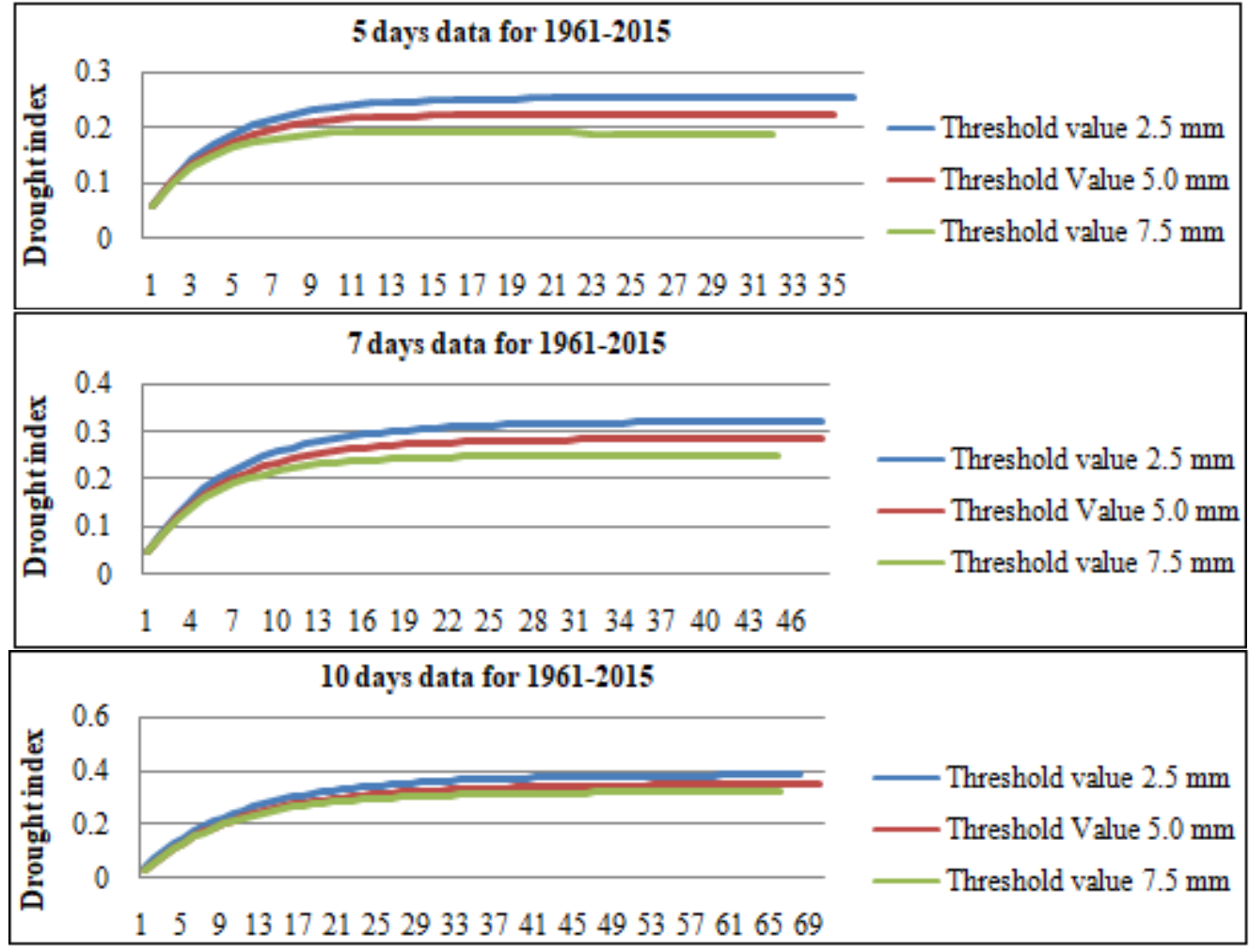

Figure 8: Drought index scenario for with different threshold value for the period 2010-2015

\subsection{Comparison among different time decade and different threshold value}

In order to find out the most drought prone time decade we summarize the number of step to become stable of Markov Chain model at their higher Transition Probability (TPM) matrix. The number of steps to become stable is listed in Table 9.

Table 9: Number of steps to become stable

\begin{tabular}{|c|c|c|c|c|c|c|c|c|}
\hline \multirow{2}{*}{ Days } & $\begin{array}{c}\text { Threshold } \\
\text { value }\end{array}$ & 1969 & 1979 & 1989 & 1999 & 2009 & 2015 & 2015 \\
\hline \multirow{4}{*}{5 days } & $2.5 \mathrm{~mm}$ & 48 & 39 & 35 & 33 & 33 & 33 & 36 \\
\cline { 2 - 10 } & $5.0 \mathrm{~mm}$ & 47 & 36 & 34 & 33 & 31 & 33 & 35 \\
\cline { 2 - 10 } & $7.5 \mathrm{~mm}$ & 44 & 35 & 31 & 31 & 30 & 29 & 32 \\
\hline \multirow{3}{*}{7 days } & $2.5 \mathrm{~mm}$ & 63 & 50 & 46 & 45 & 44 & 42 & 48 \\
\cline { 2 - 10 } & $5.0 \mathrm{~mm}$ & 67 & 48 & 46 & 46 & 42 & 44 & 48 \\
\cline { 2 - 9 } & $7.5 \mathrm{~mm}$ & 65 & 48 & 42 & 44 & 40 & 38 & 45 \\
\hline \multirow{3}{*}{ 10days } & $2.5 \mathrm{~mm}$ & 87 & 68 & 66 & 59 & 69 & 68 & 68 \\
\cline { 2 - 9 } & $5.0 \mathrm{~mm}$ & 78 & 71 & 67 & 63 & 73 & 66 & 70 \\
\cline { 2 - 9 } & $7.5 \mathrm{~mm}$ & 76 & 68 & 63 & 64 & 64 & 59 & 66 \\
\hline
\end{tabular}

From the above discussion of Table 9 we observed that for 5 days data with $2.5 \mathrm{~mm}$ threshold value the different decade showed that the decade 1961-1969, 1970-1979, 1980-1989, 1990-1999, 2000-2009 and 2010-2015 need 48, 39, 35, 33, 33 and 33 steps to become stable where the whole time period need 36 steps to become stable. So, from 5 days data with $2.5 \mathrm{~mm}$ threshold vale we may conclude that the decade 1990-1999, 2000-2009 and 2010-2015 was less drought prone than the decade 1961-1969, 1970-1979, 1980-
1989. For 5 days data the threshold value 5.0 and 7.5 also showed the similar results, i.e. the decade 1961-1969, 1970$1979,1980-1989$ was more drought prone than the decade 1990-1999, 2000-2009 and 2010-2015. Among these decades the decade 1961-1969 was maximum drought prone.

This table also indicate that for 7 days data with threshold value $2.5 \mathrm{~mm}$ the decade 1961-1969, 1970-1979, 19801989, 1990-1999, 2000-2009 and 2010-2015 need 63, 50, $46,45,44$ and 42 steps to become stable where the whole time period need 48 steps to become stable. Comparing with the whole sample data the 7 days data with $2.5 \mathrm{~mm}$ threshold value showed that the decade 1961-1969, 19701979 was more drought prone than the decade 1980-1989, 1990-1999, 2000-2009 and 2010-2015. The threshold value 5.0 and 7.5 also showed the similar pattern. Among these decades the decade 1961-1969 was maximum drought prone.

For 10 days data with $2.5 \mathrm{~mm}$ threshold value indicated that the decade 1961-1969, 1970-1979, 1980-1989, 1990-1999, 2000-2009 and 2010-2015 need 87, 68, 66, 59, 69 and 68 steps to become stable where the whole time period need 48 steps to become stable. Comparing with the whole sample data the decade the decade 1961-1969, 2000-2009 was more drought prone than the decade 1970-1979, 1980-1989, 19901999 and 2010-2015. For 10 days data with $2.5 \mathrm{~mm}$ threshold value confirm that the maximum drought prone decade 1960-1969. The other two threshold values 5.0 and 
7.5 showed that the decade 1960-1969 was the most drought prone in case of Pabna district.

This Table 9 also showed that for threshold value $2.5 \mathrm{~mm}$, the number of steps to become stable is more in case of 10 days data and it become less in case of 7 days data as well as 5 days data. For the threshold value 5.0 the 10 days data need more steps than 7 days data and 5 days data. Similar results obtained in case of threshold value $7.5 \mathrm{~mm}$.

This study will contribute to policy formulation and strategic planning in the areas such as, agricultural practices and crop diversification, investments in irrigation development works and allocation of water to different uses.

\section{Conclusion}

In Bangladesh agriculture is the main source of the development of economy where more than $70 \%$ of the working population engaged. The shortage of rains and the occurrence of drought may lead to severe food deficiency. Agricultural drought relates various characteristics of meteorological drought to agricultural impacts, focusing on precipitation shortages, differences between actual and potential evapotranspiration, soil, water deficits, reduced ground water reservoir levels etc. In this study we empirically investigate the impact of threshold value to identify the Drought Index for different decades in case of Pabna district for the time period 1961-2015. To analyze drought index in the selected region we have calculated data in decade wise and then calculated them into different time interval like 5, 7 and 10 days. Using Microsoft Excel we have separated the data in this time series format after that we use $\mathrm{R}$ program to analyze drought index under Markov chain model for threshold value $2.5 \mathrm{~mm}, 5.0 \mathrm{~mm}$ and 7.5 $\mathrm{mm}$ of rainfall. We have calculated this drought index for each time interval of wet-dry periods. At first, we find out the drought index from the first transition probability matrix (TPM). Then we estimate the higher TPM. When the higher TPM is became stable, and then we estimate drought index of that stable TPM.

From 5 days data with $2.5 \mathrm{~mm}$ threshold vale we may conclude that the decade 1990-1999, 2000-2009 and 20102015 was less drought prone than the decade 1961-1969, 1970-1979, 1980-1989. For 5 days data the threshold value 5.0 and 7.5 also showed the similar results, i.e. the decade 1961-1969, 1970-1979, 1980-1989 was more drought prone than the decade 1990-1999, 2000-2009 and 2010-2015. Among these decades the decade 1961-1969 was maximum drought prone. The threshold value 5.0 and 7.5 also confirmed that the decade 1961-1969 was most drought prone decade within this study period. Similar results were found in case of 7 days and 10 days data.

From decade rainfall data of Pabna district is affected by chronic drought proneness in the 1st TPM for threshold value $2.5 \mathrm{~mm}$ but at higher TPM both stations are affected different drought proneness some are severe, some are moderate, some are mild some are occasional. It indicates that if we calculate the drought index decade wise both stations are affected by chronic drought proneness at the 1st TPM but due to climate change at higher TPM the drought proneness are not chronic at all. The threshold value 5.0 and 7.5 also showed that Pabna district is affected by chronic drought at first TPM but at higher TPM it converted into different types of drought.

From 5 days data with $2.5 \mathrm{~mm}$ threshold vale we may conclude that the decade 1990-1999, 2000-2009 and 20102015 was less drought prone than the decade 1961-1969, 1970-1979, 1980-1989. For 5 days data the threshold value 5.0 and 7.5 also showed the similar results, i.e. the decade 1961-1969, 1970-1979, 1980-1989 was more drought prone than the decade 1990-1999, 2000-2009 and 2010-2015. Among these decades the decade 1961-1969 was maximum drought prone. The threshold value 5.0 and 7.5 also confirmed that the decade 1961-1969 was most drought prone decade within this study period. For any data point if we consider different threshold value for identifying drought index then we may conclude that if we increase the threshold value than it decrease the DI value.

So, the finding of this study is properly utilized in cultivating crops it will be the driving force for increasing production of food crops, especially rice and wheat. In severe and extremely severe drought affected areas, government Aman season will continue.

\section{Acknowledgement}

This research is funded by Faculty of Science, University of Rajshahi research project (No. A 624/5/52/RU/science14/2019-2020)

\section{References}

[1] Ahmed, R. (1991). The 1987-88 Drought selected in North Central States of the U.S.A., Geographical Bulletin, 33, 30-36.

[2] Ahmad, L., Parvaze, S., Majid, M. and Kanth, R.H. (2013). Analysis of historical Rainfall Data for drought Investigation Using Standard Preciption index (SPI) under temperate conditions of Srinagar Kashmir, Pakistan Journal of Meteorology, Vol. 13, Issue 25, 29-38.

[3] Alam, ATMJ, Rahman, M.S. and Saadat, AHM. (2013). Monitoring meteorological and agricultural drought dynamics in Barind region Bangladesh using standard precipitation index and Markov chain model. International Journal of Geomatics and Geosciences, 3 (3): 511-524.

[4] Alam. A.T.M.J., Saadat, AHM., Rahman MS and Rahman, S. (2013). Spatio- Temporal Variations of Agricultural Drought at Barind Region, Bangladesh: An Application of Markov Chain Model. Irrigation and Drainage, DOI: 10.1002/ird.1800, John Wiley \& Sons, Ltd.

[5] Alam, ATMJ, Rahman, M. S., Saadat, A. H. M. and Huq, M. M. (2012). Gamma Distribution and its Application of Spatially Monitoring Meteorological Drought in Barind, Bangladesh. 5 (2): Journal of Environmental Science and Natural Resources, 287 293.

[6] Alam. A.T.M.J., Saadat AHM., Rahman MS, and Barkotulla, M.A.B., (2011). Spatial Analysis of 
Rainfall Distribution and Its Impact on Agricultural Drought at Barind Region, Bangladesh. Rajshahi University Journal of Environmental Science. 1(1): 4050.

[7] Anderson, T. W. and Goodman, L. A. (1957). Statistical inference about Markov Chains. Annals of Mathematics and Statistics, 28: 89-110.

[8] Banglapedia (2006). National Encyclopaedia of Bangladesh. Asiatic Society of Bangladesh: Dhaka.

[9] Banik, P, Mandal. A. and Rahman. M.S. (2002). Markov chain analysis of weekly rainfall data in determining drought-proneness. Discrete Dynamics in nature and society, 7: 231-239.

[10] Briffa, K. R., Shishov,V. V., Melvin, T. M., Vaganov, E. A., Grudd,H., Hantemirov, R. M., Eronen,M. and Naurzbaev. M. M. (2008). Trends in recent temperature and radial tree growth spanning 2000 years across northwest Eurasia. Philosophical Transactions of the Royal Society B-Biological Sciences 363:2271-2284.

[11] Byun, H.R. and Wilhite, D.A. (1999). Objective Quantification of Drought Severity and Duration. Journal of Climatology, 12, 2747-2756.

[12] Heddinghaus,T. R., and Sabol, P. (1991). A review of the Palmer Drought Severity Index and where do we go from here? Proceedings, 7th Conf. on Appl. Climatol., 10-13 September 1991, Boston, American Meteorological Society, 242-246.

[13] Hussain, A.M. and Sultana, N. (1996). Rainfall distribution over Bangladesh stations during the monsoon months in the absence of depressions and cyclonic storms. Mausam 47:339-348.

[14] Islam, M.N. and Uyeda, H. (2008). Vertical variations of rain intensity in different rainy periods in and around Bangladesh derived from TRMM observations. International Journal of Climatol, 28, 273-279.

[15] Kamruzzaman, M., Rahman, Ahmed, A.T.M.S and Rahman, M.S. (2018). Spatio-temporal analysis of climatic variables in the western part of Bangladesh. Environ Dev Sustain, 20, 89-108.

[16] Kamruzzaman, M., Kabir, M.E., Rahman, A.T, Rahman, M.S. (2018). Modeling of agricultural drought risk pattern using Markov chain and GIS in the western part of Bangladesh. Environ Dev Sustain, 20, 569-588.

[17] Karim, Z., Hussain, S.G. and Ahmed, M. (1996). Assessing impacts of climate variations on foodgrain production in Bangladesh. Water, Air, and Soil Pollution, 92, 53-62.

[18] Karmakar, S. and Khatun, A. (1995). Variability and probabilistic estimates of rainfall extremes in Bangladesh during the southwest monsoon season. Mausam 46(1): 47-56.

[19] Kendall, M.G. (1975). Rank Correlation Methods. 4th Edition, Charles Griffin, London.

[20] Khalek, M.A. Rahman, M.M. , Rahman, M.S. and Md. Ayub Ali, (2020). The Performance of GARCH Modeling in Forecasting Groundwater Table Fluctuation of Northwest Bangladesh, International Journal of Statistical Sciences. Vol. 19, 2020, pp 1-18.

[21] Kripalini, R.H., Inamdar, S. and Sontakke, N.A. (1996). Rainfall variability over Bangladesh and Nepal: Comparison and connections with features over
India. International Journal of Climatology 16: 689703.

[22] Medhi, J. (1981). Stochastic process, John Wiley \& Sons.

[23] Mann, H.B. (1945). Nonparametric tests against trend. Econometrics 13: 245-259.

[24] McKee, T.B., Doesken, N.J. and Kleist, J. (1993). The relationship of drought frequency and duration to time scales. 8th Conference on Applied Climatology, 17-22 January, Anaheim, CA. 179-184.

[25] Meghla, T. and Rahman M. S. (2020). Predictive Analysis of Drought Management in Rajshahi and Dinajpur District of Bangladesh, International Journal of Statistical Sciences, Vol. 20(2), 243-256.

[26] Paul, B. K. (1998). Flood research in Bangladesh: Major findings and future research direction. In A paper presented at the 1995 Annual Meeting of the Association of American Geographers held in Chicago, IL.

[27] Palmer, W. C. (1968). Keeping track of crop moisture conditions, nationwide: the new crop moisture index. Weatherwise, vol. 21, pp. 156-161.

[28] Rahman, M.M. and Rahman, M. S. (2020). Comparison the Drought Probability at Different Decade from Northwestern Area of Bangladesh. International Journal of Science and Research (IJSR), Volume 9 Issue 11, November 2020, 1251 - 1259.

[29] Rahman, M.M. and Rahman M. S. (2020). Monitoring Drought Vulnerability at Different Time Scales: A Case Study from Rajshahi District, Bangladesh. Int. J. of Adv. Res. 8 (Nov). 404-414.

[30] Rahman, M.M. and Rahman, M. S. (2019). Performance of Different Data Mining Methods for Predicting Rainfall of Rajshahi district, Bangladesh, Proceedings of the Data Science and SDGs: Challenges, Opportunities and Realities, PP.665-669, ISBN 978-984-34-6444-6.

[31] Rahman, M.M and Rahman, M. S. (2019). Assess the Impact of Climate Change Parameters on Rice Production by Vector Autoregression Model in Rajshahi District. International Journal of Advanced Research, 7(1), 478-487.

[32] Rahman,M.M., Rahman, M S. and Shah, MAR. (2019). Impact of Climatic Parameters on Aman Rice production in Rangpur District. International Journal of Advanced Research, 6(6), 748-755.

[33] Rahman, M.M., Rahman M. S. and Sultana, S. (2018). Exploring the Climate Change Effects on Boro Rice Yields of Rajshahi District in Bangladesh. International Journal of Advanced Research, 6(8), 107116.

[34] Rahman, M. S. (2000). A rainfall simulation model for agricultural development in Bangladesh. Discrete Dynamics in Nature and Society. 5: 1-7.

[35] Rahman, M.S. and Mian, M. A. B. (2002). Stochastic Study of Asymptotic Behavior of Rainfall Distribution in Rajshahi. International Journal of Statistical Sciences, 1: 57-67.

[36] Rahman, M. S. (1999a). A stochastic simulated Markov Chain Model for daily rainfall at Barind, Bangladesh. Journal of Interdisciplinary Mathematics, 2(1): 7-32. J. Interdiscip. Math. 
[37] Rahman, M. S. (1999b). Logistic regression estimation of a simulated Markov Chain Model for daily rainfall in Bangladesh. Journal of Interdisciplinary Mathematics, 2(1): 33-40. J. Interdiscip. Math.

[38] Schmidli, J. and Frei, C. (2005). Trends of heavy precipitation and wet and dry spells in Switzerland during the 20th century. International Journal of Climatology 25(6): 753 - 771.

[39] Sen, P.K. (1968). Estimates of the regression coefficient based on Kendall's tau. Journal of the American Statistical Association 63: 1379-1389.

[40] Shahid, S. (2010). Recent trends in the climate of Bangladesh. Clim Res 42(3):185-193

[41] Shahid, S and Behrawan, H. (2008). Drought risk assessment in the western part of Bangladesh. Nat Hazard 46:391-413. doi:10.1007/s11069-007-9191-5

[42] World Meteorological Organization (WMO) (2003) Annual Report. World Meteorological Organization (WMO) Published by: WMO; 2004. Collection(s) and Series: WMO- No. 965.

[43] Zhang, Q., Xu, C-Y, Zhang, Z., Ren, G. and Chen, Y.D. (2008). Climate change or variability? The case of Yellow river as indicated by extreme maximum and minimum air temperature during 1960-2004, Theoretical and Applied Climatology 93: 35-43.

[44] Zhang, Q., Xu, C-Y. and Zhang, Z.( 2009). Observed changes of drought/wetness episodes in the Pearl River basin, China, using the standardized precipitation index and aridity index. 